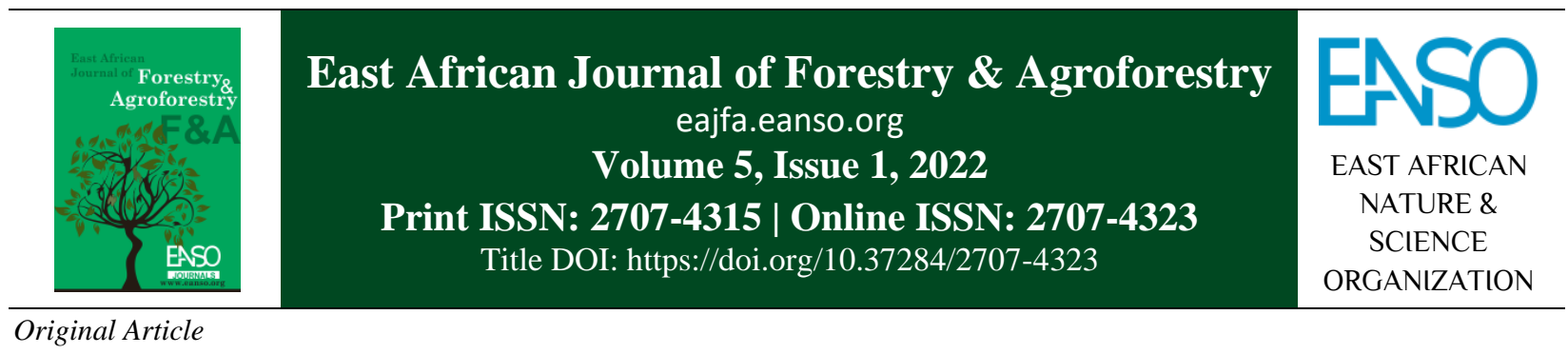

\title{
Movement, Feeding Behaviour and Threats of Colobus guereza Ruppellin at Seasonally Dry Riverine Forest of Engare-Olmotonyi and Arboreta of the Forestry Training Institute's Olmotonyi's Campus in Northern Highlands of Tanzania.
}

\author{
Dr. Canisius John Kayombo, PhD ${ }^{I^{*}}$, Tumaini Kivuyo ${ }^{1}$, Richard A. Giliba ${ }^{2}$, Sefania J. Kyando ${ }^{3}$, \\ Emmanuel Lugumira ${ }^{3} \&$ Hussein Said Gwau \\ ${ }^{1}$ Forestry Training Institute Olmotonyi, P. O. Box 943, Arusha-Tanzania \\ ${ }^{2}$ Nelson Mandela Institute of Science and Technology, P. O. Box 447, Arusha-Tanzania. \\ ${ }^{3}$ The University of Dar es Salaam, P. O. Box 35060, Dar es Salaam, Tanzania. \\ *ORCID: https://orcid.org/0000-0002-8149-895X; Author for Correspondence email: kayombocanisius@ gmail.com.
}

Article DOI: https://doi.org/10.37284/eajfa.5.1.547

\section{Date Published: ABSTRACT}

10 February 2022 The observation of feeding and movement behaviour of wild fauna is significant in the process of understanding the ecosystems. The movement

Keywords: and feeding behaviour of An assessment on the movement, feeding behaviour, and threats of Colobus guereza was done in Engare-olmotonyi

Movement, seasonally dry riverine forest and arboreta at the Forestry Training Institutes-

Feeding, Olmotonyi in northern Tanzania. The movement and feeding behaviour were

Behaviour, monitored for 30 days from mid of September to October 2020. Sleeping and waking up times, trees fed by C. guereza, and trees they slept on were

Threats, recorded and estimated for their height and canopy cover (light or dense). The

Guereza,

Colobus Guereza, human threats were also recorded. The findings revealed that C. Guereza members were waking up between $6.30 \mathrm{am}$ and $6.58 \mathrm{am}$, depending on the

Engare-Olmotonyi condition of the sky (clear or cloudy). When the sky was clear they wake up seasonally Dry,

Riverine Forest, between 6.30 and $6.45 \mathrm{am}$, and 6.45 am to 6.58 am on cloudy sky days. They slept on the highest canopy trees and were feeding on tender or mature leaves depending on the type of species. The flowers and fruits of Jacaranda mimosifolia, Albizia gummifera (J.F.Gmel.) C.A.Sm., Cussonia holstii

Arboreta,

Northern Highlands, Harms ex Engl and leaves of Lagenaria abyssinica (Hook.fil.) C.Jeffrey were found to be fed by C. guereza. As soon as they wake up, they both of them urinated. Then, young C. guereza were found to be directed to move before

Tanzania. adults just after they had urinated. The height of trees the $\mathrm{C}$. guereza were found to jump on and or sleep ranged from $24 \pm 10 \mathrm{~m}$, with an average height of $17 \mathrm{~m}$. The tallest trees ranged from a height of $24 \pm 20 \mathrm{~m}$; while the medium had a height of $\leq 20 \pm \leq 15 \mathrm{~m}$. Most of the tallest trees were Albizia gummifera (J.F.Gmel.) C.A.Sm., Jacaranda mimosifolia D.Don; Cussonia holstii Harms ex Engl.; and Eucalptys maidenii F. Muell. The threats to C.

22 | This work is licensed under a Creative Commons Attribution 4.0 International License. 
guereza were cutting of trees as their food and habitat and illegal routes that disturbed their behaviour of feeding and movement. The direction of $\mathrm{C}$. guereza movements and sleeping depend most on the trees. Further study is needed to evaluate the plant species being fed at different seasons, protect the existing trees, and restore the forest gaps.

\section{APA CITATION}

Kayombo, C. J., Kivuyo, T., Giliba, R. A., Kyando, S. J., Lugumira, E., \& Gwau, H. S. (2022). Movement, Feeding Behaviour and Threats of Colobus guereza Ruppellin at Seasonally Dry Riverine Forest of Engare-Olmotonyi and Arboreta of the Forestry Training Institute's Olmotonyi's Campus in Northern Highlands of Tanzania East African Journal of Forestry and Agroforestry, 5(1), 22-31. https://doi.org/10.37284/eajfa.5.1.547.

\section{CHICAGO CITATION}

Kayombo, Canisius John., Tumaini Kivuyo, Richard A. Giliba, Sefania J. Kyando, Emmanuel Lugumira, \& Hussein Said Gwau. 2022. "Movement, Feeding Behaviour and Threats of Colobus guereza Ruppellin at Seasonally Dry Riverine Forest of EngareOlmotonyi and Arboreta of the Forestry Training Institute's Olmotonyi's Campus in Northern Highlands of Tanzania". East African Journal of Forestry and Agroforestry 5 (1), 22-31. https://doi.org/10.37284/eajfa.5.1.547.

\section{HARVARD CITATION}

Turyahabwe, R., Asaba, J., Mulabbi, A., Mulabbi, A., Mulabbi, A., \& Paul, M. G. (2022), "Movement, Feeding Behaviour and Threats of Colobus guereza Ruppellin at Seasonally Dry Riverine Forest of Engare-Olmotonyi and Arboreta of the Forestry Training Institute's Olmotonyi's Campus in Northern Highlands of Tanzania”, East African Journal of Forestry and Agroforestry, 5(1), pp. 22-31. doi: 10.37284/eajfa.5.1.547.

\section{IEEE CITATION}

R. Turyahabwe, J. Asaba, A. Mulabbi, A. Mulabbi, A. Mulabbi, \& M. G. Paul, "Movement, Feeding Behaviour and Threats of Colobus guereza Ruppellin at Seasonally Dry Riverine Forest of Engare-Olmotonyi and Arboreta of the Forestry Training Institute's Olmotonyi's Campus in Northern Highlands of Tanzania”, EAJFA, vol. 5, no. 1, pp. 22-31, Feb. 2022.

\section{MLA CITATION}

Kayombo, Canisius John., Tumaini Kivuyo, Richard A. Giliba, Sefania J. Kyando, Emmanuel Lugumira, \& Hussein Said Gwau. "Movement, Feeding Behaviour and Threats of Colobus guereza Ruppellin at Seasonally Dry Riverine Forest of EngareOlmotonyi and Arboreta of the Forestry Training Institute's Olmotonyi's Campus in Northern Highlands of Tanzania". East African Journal of Forestry and Agroforestry, Vol. 5, no. 1, Feb. 2022, pp. 22-31, doi:10.37284/eajfa.5.1.547.

\section{INTRODUCTION}

Observing where the wild fauna lives is an important part of understanding the natural ecosystems (Malmstrom, 2010). Colobus guereza is a large, shaggy black and white monkey with a grim expression, glossy black colour with white brown and full beard framing gray-skinned face (Estes, 1999). The species is distributed across equatorial Africa and from northern Tanzania to Abyssiniaan highlands, in forest habitats from sea level to 3000 $\mathrm{m}$ a.s.l. Its ecology is on mature trees of a few different trees enables $C$. guereza to inhibit a wide range of habitats, including secondary and riparian forests with very little diversity and a prolonged dry season, unfit for other monkeys, because its needs can be met within very small forest patches on cleared land clumps of gallery forest along rivers flowing through sub-desert, and in secondary woodland (Butynsk \& De Jong, 2015).

It has been reported that the $C$. guereza are distributed in several countries including; Central African Republic, Chad, Congo, Ethiopia, Gabon, Kenya, Nigeria, Rwanda, Sudan, Tanzania, Uganda, and the Democratic Republic of the Congo (Struhsaker, 2011). C. guereza is found on a wide range, from lowland tropical rainforests, as well as riverine galleries and evergreen thicket forests (Kingdon, 2015). It has been known that the juvenile $C$. guereza are fair game for crown hawk eagles, but resident male defends troop, rushing eagle that land near (Estes, 1999). The C. guereza makes aggressive displays to other predators, including people but when thoroughly alarmed skydive into the undergrowth. C. Guereza are found in 
forests and savanna woodlands within and to the north of the moist forests of central Africa, often extending into highland or montane forests (Jensz and Finly, 2011). The C. guereza is internationally not threatened according to the IUCN, even though this species is locally threatened in parts of its range (Finley, 2011). It has been pointed that most fauna species under protected areas are meant to be recorded without collecting to sustain their life (Spawls et al., 2018).

\section{Movement and Feeding Behaviour of Colobus guereza Ruppellin}

The $C$. guereza moves with the bounding motion of a squirrel, at different speeds (Thorington and Darrow, 2000). A jumping C. guereza holds its elbows akimbo and lands on its oversized feet with legs together and flexed to absorb shocks (Barker, 2018). The troops daily ranging takes it along the regular pathway from a central sleeping tree to sunning and forage trees and back (Johanson et al. 2015). The C. guereza troops of montane populations leave their sleeping tree to sunning and forage trees and back (Estes, 1999). The C. guereza prefers feeding on young to old foliage, and fruits make up to $1 / 3$ of its diet in season, but its advantage over other monkeys including red Colobus monkeys is the ability to digest mature foliage too fibrous, distasteful, or toxic for other monkeys (Fashing, 2001). The C. guereza eats 25 to $33 \%$ of its weight in leaves per day, yet spends less time feeding than the associate velvets (30 to $45 \%$ of all time)
(Fashing, 2001). As leaf eaters, they spend 99\% of feeding time just sitting on branch plucking leaves, long tails hanging down like the lichens that clothe the cloud forest.

\section{Problem Statement and Justification}

There have been stories on the presence of Colubus guereza in several countries including Tanzania, while little researchable information exists on their movement and feeding behaviour. This study intended to assess the feeding, and movement behaviour of $C$. guereza in seasonally dry riverne forest of Engare-Olmotonyi and arboreta of Forestry Training Institute, campus in northern Tanzania. The information from this study will create awareness on their availability, movement, and plants fed and hence building strategies on how to protect the fed plants to sustain the existing $C$. guereza group.

\section{MATERIAL AND METHODS}

\section{Description of Study Site}

It is located at 37M 9636004; UTM 239677, with an altitude range of 1550 to $1700 \mathrm{~m}$ a.s.l. (Garmin GPS). It occupies the area of the Forestry Training campus, bordering the Mwinyi arboretum on the southeast, Meru plantation on the south east, north, and northeast; on the east and west it borders the buildings belonging to the Forestry Training Institute-Olmotonyi. 
Figure 1: Study area of Engare-olmotonyi seasonally dry riverine

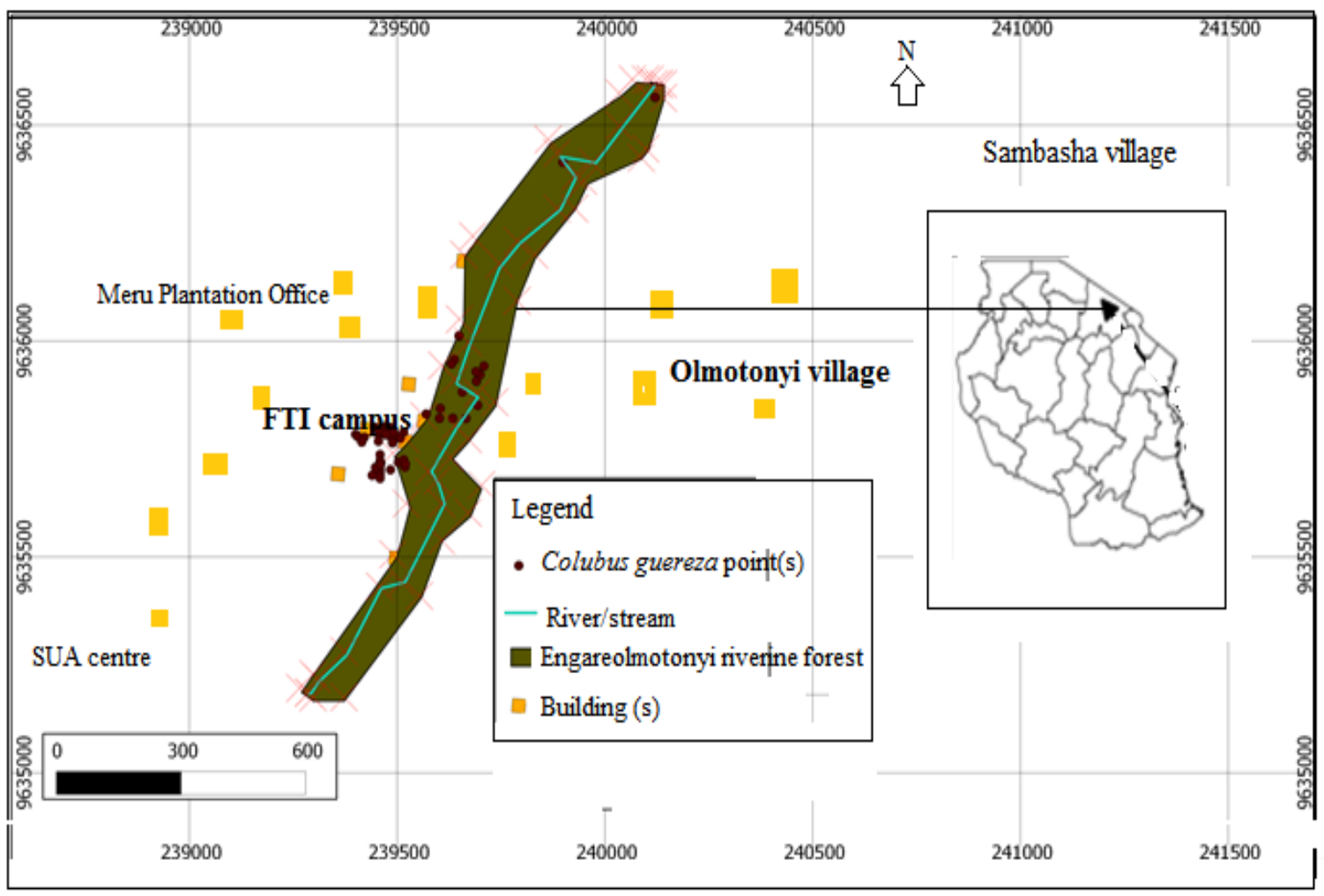

The vegetation is seasonally dry riverine dominated with trees of Albizia gummifera (J.F.Gmel.) C.A.Sm., Croton megalocarpus Hutch, Calodendrum capense (L.f.) Thunb. Acokanthera oppositifolia (Lam.) Codd., Ehretia cymosa Thonn, Croton macrostachyus Hochst. ex Delile, and Cussonia holstii Harms ex Engl. Interrupted with exotics of Jacaranda mimosifolia D.Don, Euclapyptus maidenii Fmuell. The woody climbers include Pterolobium stellatum (Forssk.) Brenan, Toddalia asiatica (L.) Lam, Caesalpinia decapetala (Roth) Alston, Phytolacca dodecandraL'Hér. The shrubs found at Engareomotonyi River at Forestry Training Institute Olmotonyi included Grewia similis K.Schum Abutilon longicuspe Hochst. ex A.Rich., Hoslundia opposite Vahl., and Maerua triphylla A.Rich. The herbaceous plants are Thunbergia alata Bojer ex Sims, Tragia brevipes Pax, and Lagenaria abyssinica (Hook. f.) C. Jeffrey (herbaceous climbers), Hypoestes aristata (Vahl) Sol. ex Roem. \& Schult., Achyranthes aspera L.,
Galinsoga parviflora Cav., Girardinia diversifolia(Link) Friis, and Ocimum gratissimum L. Grassesinclude Cynodon dactylon(L.) Pers., Setaria megaphylla (Steud) Dur. \& Schinz. The tree species within the buildings botanical garden (arboretum) are Jacaranda mimosifolia D.Don. Syzygium guineense (Willd.) D C, Persea americana Mill., Calodendrum capense, (L.f.) Thunb., Croton sylvaticus, Schinus molleL., Olea capensis L., Brachychiton rupestris (T.Mitch. ex Lindl.) K.Schum., and Prunus serotina (Kunth) Koehne

\section{Fauna Species}

The area harbours high fauna diversity including the threatened species of Xerus inauris (African pygmy squirrel) in the family Sciuridae; Centrochely ssulcata (African spurred tortoise). The others are Papio anubis (Olive baboon), Cryptomys hottentotus (African Mole-rat), the Nectarinia venusta (Variable sunbird), Centropus superciliosus

25 This work is licensed under a Creative Commons Attribution 4.0 International License. 
East African Journal of Forestry and Agroforestry, Volume 5, Issue 1, 2022

Article DOI: https://doi.org/10.37284/eajfa.5.1.547

(White browed caucal) and Cercopithecus mitis (Plate 1), a variety of insects.

Plate 1: Fauna of Engare-olmotonyi riverine and within building forest

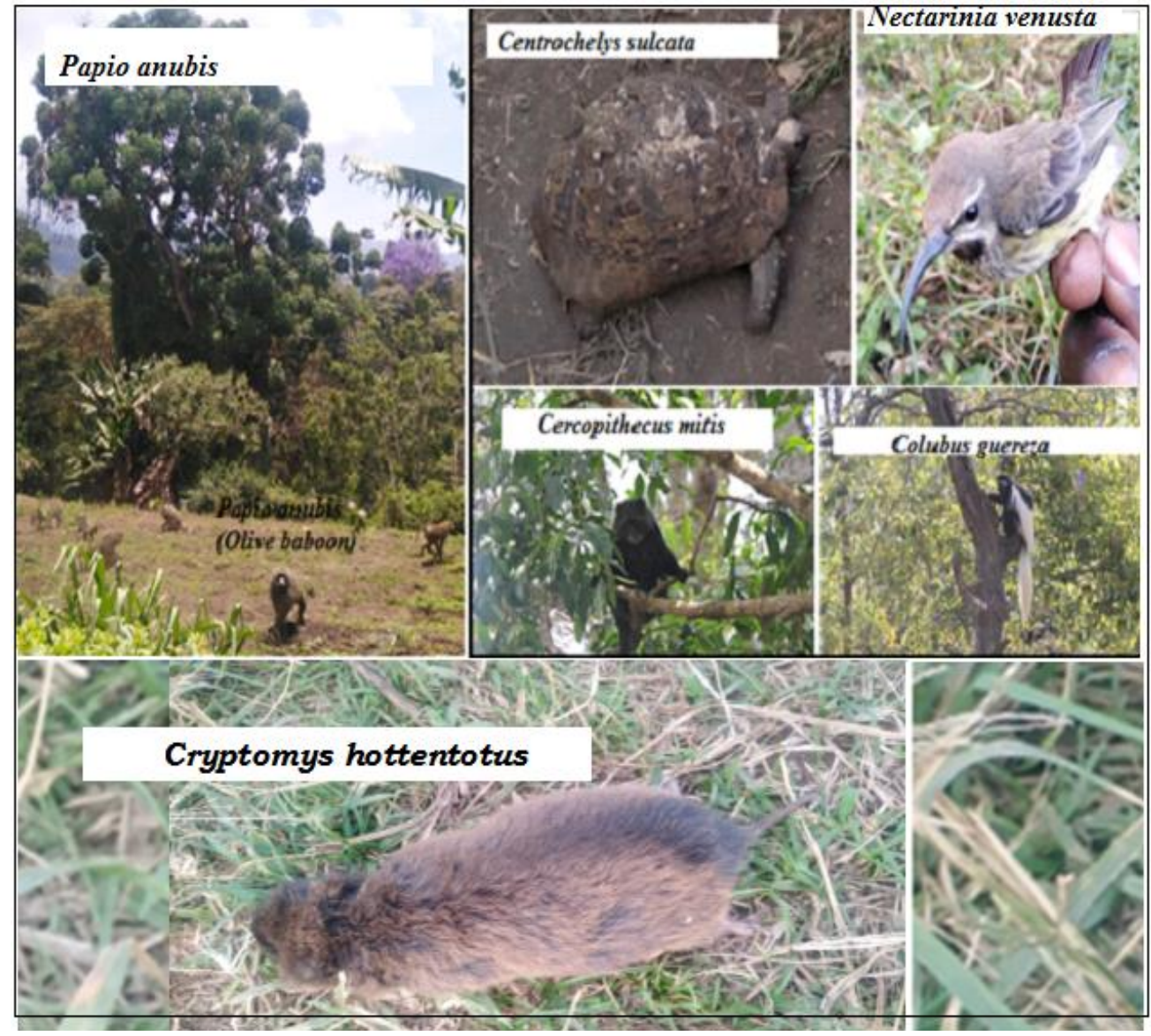

\section{Data Collection Method and Analysis}

A survey on the movement and feeding behaviour of Colobus guereza was done in the Afromontane vegetation of Engare-olmotonyi seasonally dry riverine forest at the Forestry Training Institute's campus in northern Tanzania. The movements and feeding behaviours were monitored for 30 days from mid of September 2020 to 16October 2020, from 6.00 am to $7.00 \mathrm{pm}$. The sleeping and waking up times, trees fed by $C$. guereza, and trees they slept on were recorded and estimated for their height and canopy cover (light or dense). The disturbances discouraging their stay were also recorded.
The min-height of trees was calculated through $A H T=\frac{T H A T}{T N T}$ where AHT $=$ average height of trees; THAT $=$ total height of all trees; TNT $=$ total number of stems.

\section{RESULTS}

\section{Waking up and Sleeping Time of Colobus guereza}

The waking up time is from 6.30 am to 6.58 depending on the condition of the sky. When the sky is clear they wake up between 6.30 and $6.45 \mathrm{am}$, but when the sky is clouded, they wake up from beyond $6.45 \mathrm{am}$ to $6.58 \mathrm{am}$. If the sky is cloudy and drizzly,

26 | This work is licensed under a Creative Commons Attribution 4.0 International License. 
they may wake up but continue hiding in dense trees.

\section{Sleeping Time and Place}

The first action they make before going to sleep nearly all of them urinate. They sleep on tall trees with an average height of $17 \mathrm{~m}$ tall and beyond, at the highest canopy. The canopy cover may range from light but not very light, and on dense tree canopies. The trees preferred included Jacaranda mimosifolia D.Don, Albizia gummifera (J.F.Gmel.) C.A.Sm., and Cussonia holstii Harms ex Engl. These trees are tall and their tender leaves and flowers are also preferred as their food. They are 12 in total, and when sleeping each of them goes on a separate branch of the same tree or nearby tree in case the tree has fewer branches, with the oldest of them that seem to bet biggest of all sleeps some distance from all others on a nearby separate tall tree. And if the tree canopy does not satisfy the carrying capacity, they separate into two groups of five (5) and seven (7).

\section{Movement Behaviour}

In the morning after urinating the young ones are directed to start jumping forward towards the direction of preference and the biggest jump lasts. Their movement is on trees, except wherever there are gaps they could walk for a short distance and jump on the tree they want to feed on or just to pass on to the next trees. As they woke up after urinating, they start feeding on the tree of preference, all the way to the afternoon. The height of trees the $C$. guereza were found to jump on and or sleep ranged from $24 \pm 10 \mathrm{~m}$, with an average height of $17 \mathrm{~m}$. The tallest trees ranged from a height of $24 \pm 20 \mathrm{~m}$; while the medium had a height of $\leq 20 \pm \leq 15 \mathrm{~m}$. Most of the tallest trees were Albizia gummifera (J.F.Gmel.) C.A.Sm; Jacaranda mimosifolia D.Don; Cussonia holstii Harms ex Engl; and Eucalptys maidenii F. Muell .

\section{Plate 2: Movement behaviour of Colobus guereza}
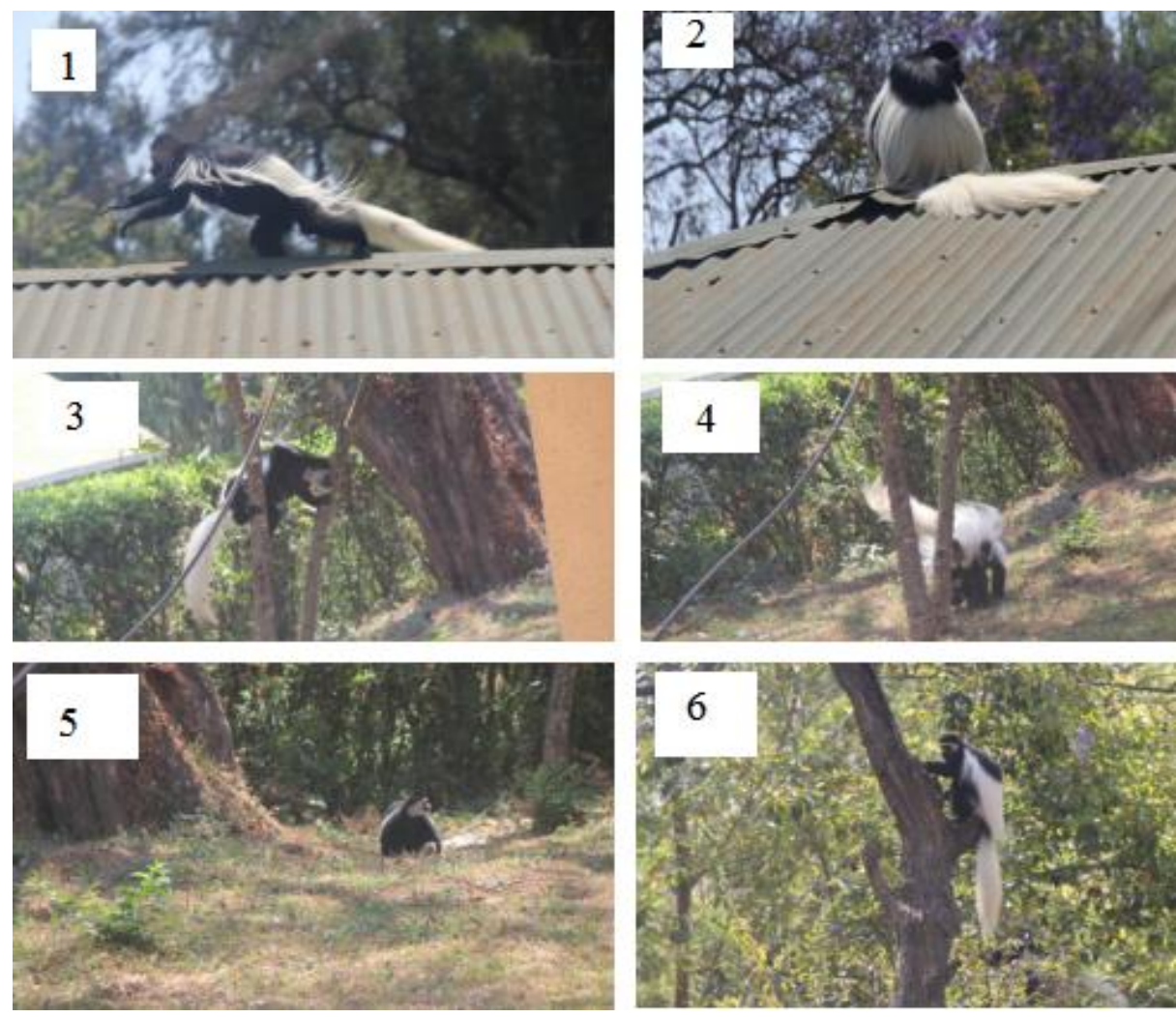

27 This work is licensed under a Creative Commons Attribution 4.0 International License. 
In the evening from after $3.00 \mathrm{pm}$ to before $6.40 \mathrm{pm}$, they may spend few minutes walking or playing with each other on the ground, and then jump on the trees as they see either any person or anything walking around.

\section{Feeding Behaviour and Parts Fed by Colobus guereza}

The $C$. guereza feed on plant parts while also jumping from one branch to another on the same tree they are feeding on. They sometimes feed even on herbaceous plant parts especially the herbaceous climbers like on leaves of Lagenaria abyssinica (Hook.f) Jeffrey (Table 1), trees tender and mature leaves, and fruits (Table 1).

Plate 3: Colobus guereza feeding on trees

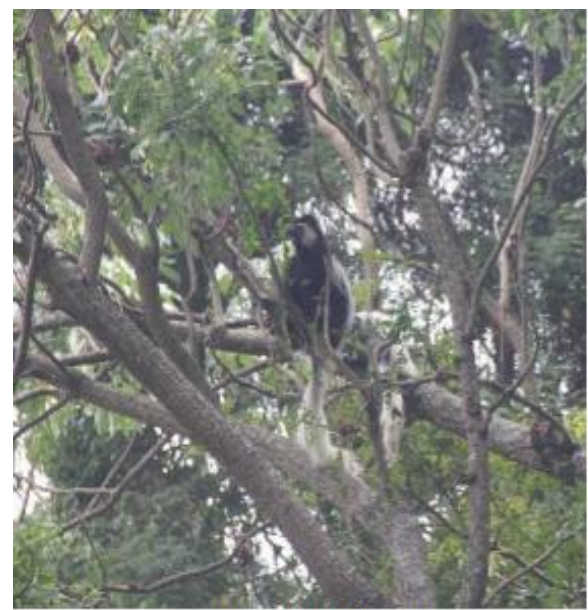

Cussonia holstii

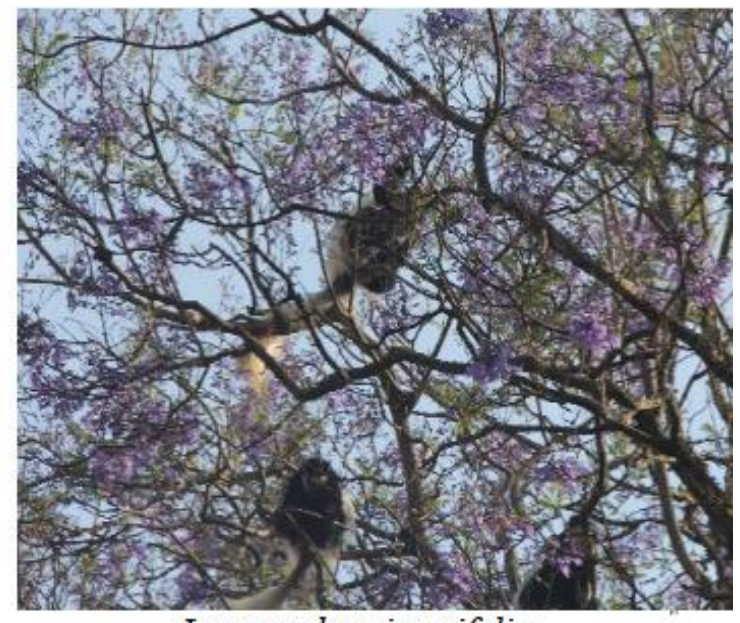

Jacaranda mimosifolia
Of all plants, Cussonia holstii (Plate 3) was known to be the most preferred tree species as food for them, followed by Jacaranda mimosifolia D.Don (Plate 3), Pterolobium stellatum (Forssk.) Brenan,
Albizia gummifera (J.F.Gmel.) C.A.Sm, Vachelia xanthophloea Benth, Lagenaria abyssinica (Hook.f) Jeffrey and Ehretia cymosa Thonn was found to be the least preferred.

Table 1: Table of fed plants

\begin{tabular}{|c|c|c|c|c|c|}
\hline \multirow[b]{2}{*}{ Botanical name } & \multicolumn{3}{|c|}{ Part they fed on } & \multirow[b]{2}{*}{ Flower (FL) } & \multirow[b]{2}{*}{$\%$} \\
\hline & Observed & Leaves (TL/LF) & Fruit(s) (FR) & & \\
\hline Albizia gummifera (J. F. Gmel.) C. A. Sn & & TL & & & 7.3 \\
\hline Bersama abyssinicaFresen & 1 & & FR & FL & 1.8 \\
\hline Cussonia holstii Harms ex Engl. & 23 & $\mathrm{TL}$ & FR & & 41.8 \\
\hline Ehretiacymosa Thonn & 1 & $\mathrm{LF}$ & FR & & 1.8 \\
\hline Jacaranda mimosifolia D.Don & 17 & $\mathrm{TL}$ & & FL & 30.9 \\
\hline Lagenaria abyssinica (Hook.f) Jeffrey & 2 & $\mathrm{LF}$ & & & 3.6 \\
\hline Pterolobium stellatum (Forssk.) Brenan & 5 & $\mathrm{TL}$ & FR & & 9.1 \\
\hline Vachelia xanthophloea Benth & 2 & $\mathrm{TL}$ & & & 3.6 \\
\hline Total & 55 & 8 & 4 & 2 & 100 \\
\hline
\end{tabular}

28 This work is licensed under a Creative Commons Attribution 4.0 International License. 
The Fabaceae family had the largest number of species preferred by Colbus guereza, while the rest had only one species each (Table 2). This study revealed that a total of two families (Fabaceae and Cucurbitaceae) are known to accommodate species edible by human beings too, while three of them were not known to be eaten by human beings as food but also not known significantly to contain toxic constituent.

Table 2: Total number of species per family

\begin{tabular}{lll}
\hline Family & Total species fed & \% \\
\hline Fabaceae & 3 & 37.5 \\
Araliaceae & 1 & 12.5 \\
Boraginaceae & 1 & 12.5 \\
Bignoniaceae & 1 & 12.5 \\
Cucurbitaceae & 1 & 12.5 \\
Melianthaceae & 1 & 12.5 \\
\hline Total & $\mathbf{8}$ & $\mathbf{1 0 0}$ \\
\hline
\end{tabular}

\section{Threats of Colobus guereza and their Habitat}

The identified threats were tree cutting that removes their habitats and routes as they always stay, feed, and sleep on tall trees, and the gaps disturb their behaviour of movement; uncontrolled solid disposal may damage their habit; buildings involve the removal of trees and hence damaging tall trees that among them offer food for them; footpaths when extended too much can damage seedlings, saplings and offer access to the interior trees that are being cut because of being accessible easily; car roads block the pathways of $C$. guereza.

\section{DISCUSSION}

The findings on separate sleeping of the $C$. guereza at Engare-olmotonyi seasonally dry riverine forest matches with the findings by Reichard (1997) who found that most primate group members usually slept in separate trees, and, except for females with infants, they never shared a sleeping place; the majority of sleeping trees were used only once, and fewer were selected repeatedly by the same or other group members, and usually females with infants went into a sleeping tree first, then juveniles and last were mostly sub-adult and adult males. Groups of $C$. guereza often sleep in dense trees near commonly used food sources, which might reduce the time and energetic costs of travel (Hippel, 1998). The waking up range of $C$. guereza depends on the clouds cover, whether open or closed sky. When the sky is closed the darkness stays longer than normal days of open sky and hence delaying the working uptime. The sleeping is also dependent on the clouds cover; when the sky is cloudy the darkness starts earlier than when it is open sky. $C$. guereza feed on a variety of plant species (Harris \& Chapman, 2007). Gron (2009) found that C. guereza was feeding on fruits and leaves of the tree of preference. Fashing (2000) pointed out that $C$. guereza usually feeds on leaves and fruits, and rarely on barks of trees. The other studies such as by Ibrahim (2017) found that $C$. guereza was feeding on leaves, fruits, and flowers, and bark. It has been pointed out that the geographical location of Black and white colobus monkey is among factors threatening the $C$. guereza, as they usually live mainly in third-world countries, so economics is a factor that affects their conservation, because home countries have high demand on the forest natural resources including land for cultivation and wood materials for construction, and land for settlement (Amani, 2006). The study done by Gron (2009) revealed that threats from human disturbances 
including grazing damaged the undergrowth in the forests.

\section{CONCLUSION AND RECOMMENDATIONS}

Colobus guereza are born on trees, live on trees and die on trees. The movement and feeding depend on the preference and part of a particular tree. The tallest trees are most preferred for movement and sleeping, while ground movements are only for a short time and especially when crossing the tree lines gaps or across buildings. Waking times depend on the state of the sky, whether clear or cloud. Human activities threaten their habitats and food source 1 of trees for various uses. Conservation strategies such as restoration of forest gaps, regular patrols, and ecotourism as non-woody income generating interventions are encouraged.

\section{REFERENCES}

Amani, K. (2006). Habitat Use and Conservation Status of Black-And-White Colobus (Colobus Angolensis) and Blue Monkeys (Cercopithecus Mitis) in Amani Nature Reserve, Tanzania. Doctoral dissertation. University of Dar es Salaam.

Barker, L.A. (2018). Biomechanical Analysis of Jumping: The Influence of External Load and

Countermovement Depth on Deceleration Strategies and Performance. UNLV Theses, Dissertations, Professional Papers, and Capstones. 3213. http://dx.doi.org/10.34917/13 5613568373.

Butynski, T. M., \& de Jong, Y. A. (2015). Distribution and conservation status of the Mount Kilimanjaro guereza Colobus guereza caudatus Thomas, 1885. Primate Conservation, 2015(29), 107-113.

Estes, R. D. (1999). The safari companion: a guide to watching African mammals including hoofed mammals, carnivores, and primates. Chelsea Green Publishing.

Fashing, P. J. (2001). Feeding ecology of guerezas in the Kakamega Forest, Kenya: the importance of Moraceae fruit in their diet. International Journal of Primatology, 22(4), 579-609.

Gron, K. J. (2008). Primate Factsheets: Guereza (Colobus guereza) taxonomy, morphology. \& ecology.

Harris, T. R., \& Chapman, C. A. (2007). Variation in diet and ranging of black and white colobus monkeys in Kibale National Park, Uganda. Primates, 48(3), 208-221.

Jensz, K. and Finley, L. (2011) Species profile for Colobus guereza. Latitude 42 Environmental C onsultants Pty Ltd. Hobart, Tasmania.

Johnson, C., Piel, A.K., Forman, D., Stewart, F.A., and Kind, A.J. (2015). The ecological

determinants of baboon troop movements at local and continental scales. Movement Ecology, 3:14 DOI 10.1186/s40462-015-0040-y.

Ibrahim, H., Bekele, A., \&Yazezew, D. (2017). Population structure and feeding ecology of Guereza (Colobus guereza) in Borena-Sayint National Park, northern Ethiopia. International Journal of Biodiversity and Conservation, 9(11), 323-333.

Jensz, K., \& Finley, L. (2011). Species profile for Colobus guereza. Hobart, Tasmania: Latitude, 42.

Kingdon, J. (2015). The Kingdon field guide to African mammals. Bloomsbury Publishing.

Malmstrom, C. (2010) Ecologists Study the Interactions of Organisms and Their Environment. Nature Education Knowledge 3(1 $0): 88$. 
Spawls, S., Howell, K., Hinkel, H., \&Menegon, M. (2018). Field guide to East African reptiles. Bloomsbury Publishing.

Struhsaker, T. T., \& Oates, J. F. (2011). Comparison of the behavior and ecology of red colobus and black-and-white colobus monkeys in Uganda: a summary. In Socioecology and psychology of primates (pp. 103-124). De Gruyter Mouton.

Thorington, R.W., and Darrow, K. (2000). Anatomy of the Squirrel Wrist: Bones, Ligaments,

and Muscles Journal of Morphology, 246:85-102.

Von Hippel, F. A. (1998). Use of sleeping trees by black and white colobus monkeys (Colobus guereza) in the Kakamega Forest, Kenya. American Journal of Primatology, 45(3) , 281-290.

31 This work is licensed under a Creative Commons Attribution 4.0 International License. 